\title{
Partitioning of Allozyme Diversity in Wild Populations of Malus sieversii L. and Implications for Germplasm Collection
}

\author{
Warren F. Lamboy ${ }^{1,2,3}$, Jing Yu' $\mathbf{Y}^{2}$ Phil L. Forsline', and Norman F. Weeden ${ }^{2}$ \\ Cornell University, Geneva, NY 14456-0462 \\ Additional index words. apple, isozymes, Nei's genetic identity, analysis of molecular variance, cluster analysis
}

\begin{abstract}
One of the primary progenitors of the cultivated apple is Malus sieversii $\mathrm{L}$., a species native to the forested regions of central Asia. Despite the horticultural importance of $M$. sieversii, little is known about genetic variation in this species. In this study, allozyme diversity at 18 loci was determined for 259 seedlings belonging to 31 sib families, each consisting of the set of offspring from a different open-pollinated maternal (seed) parent. Maternal parents belonged to 14 populations from four geographic regions. Genetic diversity statistics were computed from the resulting allele and phenotype frequencies. Cluster analysis of sib families showed that there was some grouping based on geographic region, but 16 of the sib families were most closely related to sib families from other regions. Analysis of molecular variance (AMOVA) indicated that $85 \%$ of the enzyme variability was due to differences among sib families within populations and $15 \%$ was due to differences among regions. No variability could be assigned to differences among populations within regions. In addition, no alleles were found that were fixed in a region and unique to that region. These results suggest that plants belonging to $M$. sieversii effectively form a panmictic population. Consequently, a thorough sampling of a few large populations will efficiently capture most of the genetic diversity present in wild $M$. sieversii.
\end{abstract}

Malus sieversii is a wild, putatively outcrossing species of apple that is native to central Asia, where it forms forests in which it is the dominant tree. Because $M$. sieversii is the primary progenitor of the cultivated apple, M. ×domestica Borkh. (Morgan and Richards, 1993), it is important in apple breeding, genetics, evolution, and germplasm conservation.

Until recently, germplasm of this species has not been readily available to researchers. In 1989 and 1993, however, collecting expeditions to central Asia (Forsline et al., 1994) generated 42 new seed accessions of $M$. sieversii that are now accessible to researchers as part of the USDA-ARS National Plant Germplasm System. Because of the physical difficulties involved in collecting germplasm in the rugged, mountainous, and relatively inaccessible locations where $M$. sieversii is found and the high costs of conducting such expeditions, it is necessary to consider more efficient germplasm collecting strategies for future expeditions. To develop such strategies, information on the partitioning of genetic diversity within and among populations of $M$. sieversii is required.

Received for publication 16 Apr. 1996. Accepted for publication 11 June 1996. We are grateful to A.D. Djangeliev, Interbranch Laboratory for the Protection of Germplasm, Academy of Sciences, Almaty, Kazakhstan, for arranging and participating in the germplasm collection expeditions. We recognize the efforts of the late Calvin Sperling for organizing and participating in the first collecting trip and for his support of apple expeditions in Central Asia. We thank the members of the 1989 and 1993 expedition teams for their assistance: H. Aldwinkle, E. Dickson, G. Mink, and D. Noiton. L. Excoffier generously provided the AMOVA1.5 program and gave advice on its use. P.E. Smouse supplied statistical references to the methods used in AMOVA1.5. Susan Brown, Stan Hokanson, Amy Iezonni, James Luby, James McFerson, three anonymous reviewers, and the associate editor supplied valuable comments that considerably improved the manuscript. This work was funded in part by USDA Specific Cooperative Agreement \#58-0500-4-F100. The USDA-ARS National Plant Germplasm System provided support for plant exploration trips to Kyrgyzstan and Kazakhstan. Mention of a proprietary product does not constitute an endorsement or recommendation for use by the U.S. Dept. of Agriculture. The cost of publishing this paper was defrayed in part by the payment of page charges. Under postal regulations, this paper therefore must be hereby marked advertisement solely to indicate this fact.

${ }^{1}$ USDA-ARS Plant Genetic Resources Unit.

${ }^{2}$ Dept. of Horticultural Sciences.

${ }^{3}$ To whom reprint requests should be addressed.
Unfortunately, information on genetic diversity in $M$. sieversii does not exist. Isozymes have been used to examine genetic diversity in several tree fruit species (Torres, 1989), including Malus (Dickson et al., 1991). The latter study did not treat $M$. sieversii, however, rather the North American species M. angustifolia (Aiton) Michaux, M. coronaria L., M. ioensis (Alph. Wood) Britton, and $M$. fusca (Raf.) Schneider. Other recent Malus isozyme studies have focused primarily on cultivar identification (Barnes, 1993; Bournival and Korban, 1987; Marquard and Chan, 1995; Menendez et al., 1986; Weeden and Lamb, 1985) or genetic linkage and isozyme inheritance (Chevreau and Laurens, 1987; Weeden and Lamb, 1987). Thus, to provide background genetic diversity information that can be used to develop a more efficient collecting strategy for wild populations of $M$. sieversii, we undertook a study of allozyme diversity in the apple germplasm collected in 1989 and 1993.

The purpose of this work was 3-fold: 1) to describe the allozyme diversity in $M$. sieversii collected in 1989 and 1993 from four distinct geographic regions; 2 ) to determine if most of the observed diversity in this species is found among regions, among populations within regions, or among sib families within populations; and 3 ) to use this information to devise strategies for future collections of wild germplasm of $M$. sieversii or other wild species having a similar partitioning of genetic diversity.

\section{Materials and Methods}

Isozyme patterns were determined for 259 seedlings belonging to $31 \mathrm{sib}$ families, each consisting of the set of offspring from a different open-pollinated maternal (seed) parent. The proportion of half-sibs and full-sibs in a sib family was not determined. Maternal parents belonged to 14 populations from four geographic regions (Fig. 1). For our purposes, a population is defined as a group of plants collected from a distinct site. Collections were made in Uzbekistan in 1989 and in Kazakhstan (Topolevka and Lepsinsk areas) and Kyrgyzstan in 1993. One to six sib families were analyzed from each population (Table 1). Each sib family consisted of one to ten offspring (Table 1). 


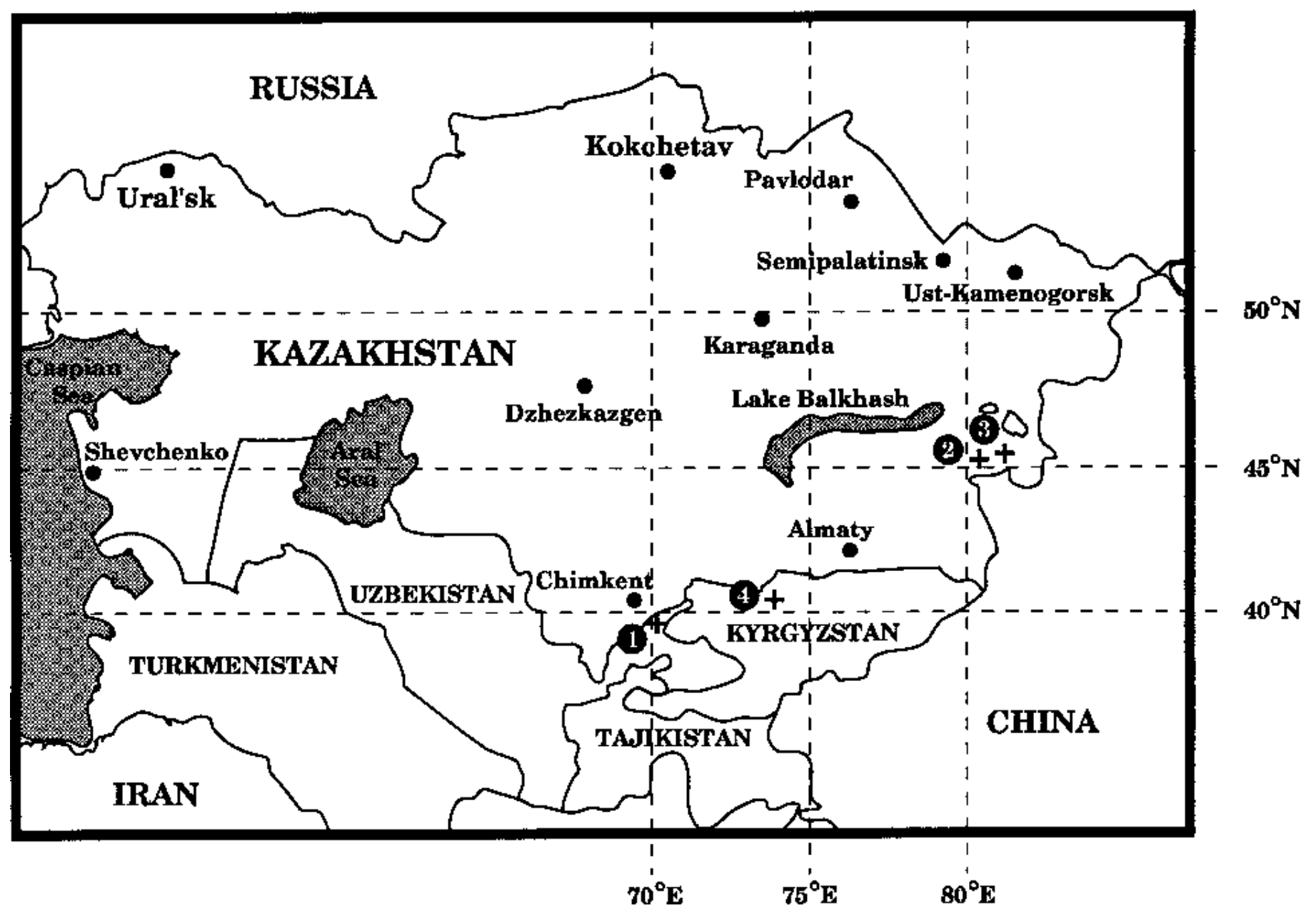

Fig. 1. Map of Kazakhstan, with collection regions indicated by numerals. Region $1=$ Uzbekistan; Region $2=$ Kazahkstan-Topolevka area; Region $3=$ KazahkstanLepsinsk area; Region 4 = Kyrgyzstan.

Numbers of offspring and sib families were limited for several reasons. First, the number of maternal parents from which fruit could be taken was limited during both expeditions by the usual logistical factors affecting field collection in relatively inaccessible regions, including the weight of fruit that can be carried by one individual, difficulty in visiting remote areas, lack of field laboratory facilities, and problems in rapidly and efficiently extracting viable seed without damage. Second, in 1993, only about $5 \%$ of the potential maternal parents actually bore fruit because of a severe prebloom spring frost that damaged the gynoecium in many flowers (Forsline, 1995). Third, for unknown reasons, germination of seeds collected in 1989 was extremely poor; in the worst case only 1 seed in 20 germinated. Finally, because seed was needed for inclusion in the Malus genetic resources collection in Geneva, N.Y., for backup at the USDA-ARS National Seed Storage Laboratory in Fort Collins, Colo., and for experimental use by other researchers, only 20 seeds from each sib family were available for the analyses reported here. With a maximum successful studied. germination rate of $50 \%$, at most 10 seedlings from each sib family were used.

Seeds were stratified for $90 \mathrm{~d}$ at $2{ }^{\circ} \mathrm{C}$ and then placed on moistened blotter paper in plastic containers at $10{ }^{\circ} \mathrm{C}$ for germina-

Table 1. Geographic origin and germplasm identification numbers of Malus sieversii accessions

\begin{tabular}{lccl}
\hline \hline $\begin{array}{l}\text { Geographic } \\
\text { region }\end{array}$ & Year & $\begin{array}{c}\text { Population } \\
\text { no. }\end{array}$ & $\begin{array}{l}\text { IDs }^{2} \text { of maternal parents } \\
\text { (no. of offspring in a sib family) }\end{array}$ \\
\hline Uzbekistan & 1989 & 1 & $3262(1)$ \\
& & 2 & $3264(8), 3265(3)$ \\
Kazakhstan-Topolevka & 1993 & 3 & $3267(2), 3268(4), 3269(3), 3270(6)$ \\
& & 1 & $3535(10), 3536(10), 3537(10)$ \\
& & 3 & $3538(10)$ \\
Kazakhstan-Lepsinsk & 1993 & 4 & $3539(10)$ \\
& & 1 & $3540(6), 3541(10), 3543(10)$ \\
& & 2 & $3556(10)$ \\
Kyrgyzstan & 3 & $3558(10)$ \\
& & 4 & $3559(10), 3560(10), 3561(10)$ \\
& 1993 & 1 & $3574(10), 3575(10), 3576(10), 3577(10)$, \\
& & & $3578(10), 3579(10)$ \\
& & 2 & $3580(10), 3581(6), 3585(10)$ \\
\hline
\end{tabular}

${ }^{\mathrm{z} L o c a l}$ Geneva Germplasm Repository number. 
tion. After emergence of the radicle ( 5 to $10 \mathrm{~mm}$ long), the seeds were planted in $13-\mathrm{cm}$ pots containing artificial soil medium and grown in the greenhouse under a $16 \mathrm{~h}$ light/ $8 \mathrm{~h}$ dark photoperiod and $18{ }^{\circ} \mathrm{C} / 13^{\circ} \mathrm{C}$ day/night temperature regime. Extracts from young, expanding leaves were subjected to horizontal starch gel electrophoresis (Weeden and Lamb, 1985). Two buffer systems were used for electrophoresis: a Tris citrate-lithium borate system at $\mathrm{pH} 8.3$ (Selander et al., 1971) and a histidine buffer at $\mathrm{pH} 6.5$ (Cardy et al., 1980). In addition to the six enzyme systems used by Weeden and Lamb (1985), phosphoglucomutase (PGM;EC 2.7.5.1) and peroxidase (PRX; EC 1.11.1.7) (Wendel and Weeden, 1989) were analyzed. The former was assayed on a slice from the histidine gel, while the latter was assayed on a slice from the Tris citrate-lithium borate gel.

Genotypes at the loci Aat-c, Aat-p, Dia-2, Idh-1, Pgd-c, Pgd-p, Pgm-c1, Pgm-c2, Pgm-p1, Tpi-c2, Tpi-p1, and Tpi-2 were scored directly from the isozyme phenotype using genetic information presented in Weeden and Lamb $(1985,1987)$ and Manganaris (1989). Patterns obtained for Dia-1, Gpi-c1, Gpi-c2, Gpi-p, Pgm3 , and $\operatorname{Pr} x-1$ were scored as phenotypes, there being no previous genetic analysis of these loci. Locus naming conventions follow those of Weeden and Lamb (1985, 1987) or Manganaris (1989). Loci whose suffices begin with $c$ are known to code for cytosolic isozymes, while those whose suffices begin with $p$ are known to code for plastid-specific isozymes. If more than one plastid or cytosolic isozyme is known, a numeral has been added as the last character of the suffix, with smaller numbers indicating loci coding for more anodal (faster moving) isozymes. The subcellular locations of the products of loci whose suffices are solely numerals have not been determined.

The basic unit of statistical analysis was a sib family from an open-pollinated maternal parent. Allelic frequencies within the sib family were computed as the number of times an allele was found at a locus (homozygotes had the allele counted twice, and heterozygotes had each allele counted once) divided by twice the number of offspring in the sib family. For each sib family, an allele

Table 2. Allele and phenotype diversity per locus for all regions and populations of Malus sieversii.

\begin{tabular}{lcccc}
\hline \multicolumn{1}{c}{ Avg no. of } & Alleles & Phenotypes & $\begin{array}{c}\text { Alleles or } \\
\text { phenotypes } \\
\text { per locus }\end{array}$ \\
\hline Region & Population & per locus & per locus & $\begin{array}{c}\text { per locus } \\
\text { Uzbekistan }\end{array}$ \\
All populations in region & 2 & 1.17 & 1.00 & 1.11 \\
Kazakhstan-Topolevka & 3 & 1.67 & 1.83 & 1.72 \\
& 1 & 1.92 & 2.17 & 2.00 \\
& 2 & 2.00 & 2.33 & 2.11 \\
& 3 & 1.83 & 1.67 & 2.06 \\
All populations in region & 4 & 1.75 & 1.83 & 1.83 \\
Kazakhstan-Lepsinsk & 5 & 2.25 & 1.67 & 1.78 \\
& 1 & 1.83 & 1.83 & 2.06 \\
& 2 & 2.58 & 2.33 & 1.83 \\
All populations in region & 3 & 1.50 & 1.33 & 2.50 \\
Kyrgyzstan & 4 & 1.92 & 1.67 & 1.44 \\
& & 1.42 & 1.17 & 1.83 \\
All populations in region & 2 & 2.17 & 1.50 & 1.73 \\
All regions & & 2.17 & 1.67 & 2.00 \\
& & 2.33 & 1.83 & 2.06 \\
& & 2.50 & 2.00 & 2.22 \\
& & 2.75 & 3.00 & 2.39 \\
& & & & 2.83 \\
\hline
\end{tabular}

that was not detected at a locus was assumed to have a frequency of zero. Phenotype frequencies were computed as the proportion of offspring in the sib family exhibiting a particular phenotype.

Nei's genetic identity, I, (Nei, 1972) was used as the measure of similarity between two sib families, with either allelic frequencies or phenotype frequencies used in the computation, whichever was appropriate for the particular locus. The genetic distance between sib families was computed as $D=1-I$; where $D$ is simply the genetic identity transformed into a distance measure, which is required by the analysis of molecular variance (AMOVA) (Excoffier et al., 1992). The computer program APPLEGEN, written by Lamboy in the GAUSS programming language (Edlefsen and Jones, 1986), was used to compute genetic identities and genetic distances.

Genetic identities between sib families were analyzed by unweighted pair-group method using arithmetic averages (UPGMA) cluster analyses (Sneath and Sokal, 1973). The cluster analysis was carried out and the phenogram was constructed using the program NTSYS (Rohlf, 1994). Genetic distances were used in AMOVA, a statistical method that partitioned genetic distance among geographic regions, among populations within geographic regions, and among sib families within populations. AMOVA analysis was carried out using the program AMOVA1.5 (Excoffier, 1993).

\section{Results}

Isozyme phenotypes of $M$. sieversii plants were so similar to those reported for $M$. $\times$ domestica that most polymorphisms could be assigned genotypes based on previous genetic studies in the cultivated apple (Weeden and Lamb, 1985; 1987). Genotypes at 12 loci were scored, as were phenotypes for six additional areas of activity in four enzyme systems. A greater average number of alleles generally was found in those regions and populations from which higher numbers of plants were sampled (Table 2). The smallest average number of alleles plus phenotypes (1.11) was found in the Uzbekistan population 1, where the sib family consisted of only a single seedling (Table 1). The next smallest number, 1.33, was found for the Lepsinsk population 3, where 10 offspring were sampled (Table 1). The relationship between number of alleles and number of plants sampled, however, was not absolute. For example, Kyrgyzstan population 2 showed the greatest mean number of alleles plus phenotypes detected (2.22), even though only 26 offspring were sampled there from three maternal parents (Table 1).

Matrices of genetic identities and distances between sib families (data not shown) were computed from the allele and phenotype frequency data. When identities were used in a UPGMA cluster analysis, the phenogram in Fig. 2 was obtained. Sib families did not group strongly by region. In fact, the only groups containing plants from a single region were six small clusters of two or three plants each (indicated by vertical bars in Fig. 2). Any cluster containing more than three sib families included sib families from two or more regions (Fig. 2). Thus, although $15 \mathrm{sib}$ families in six small clusters were most closely related to 
Nei's Genetic Identity

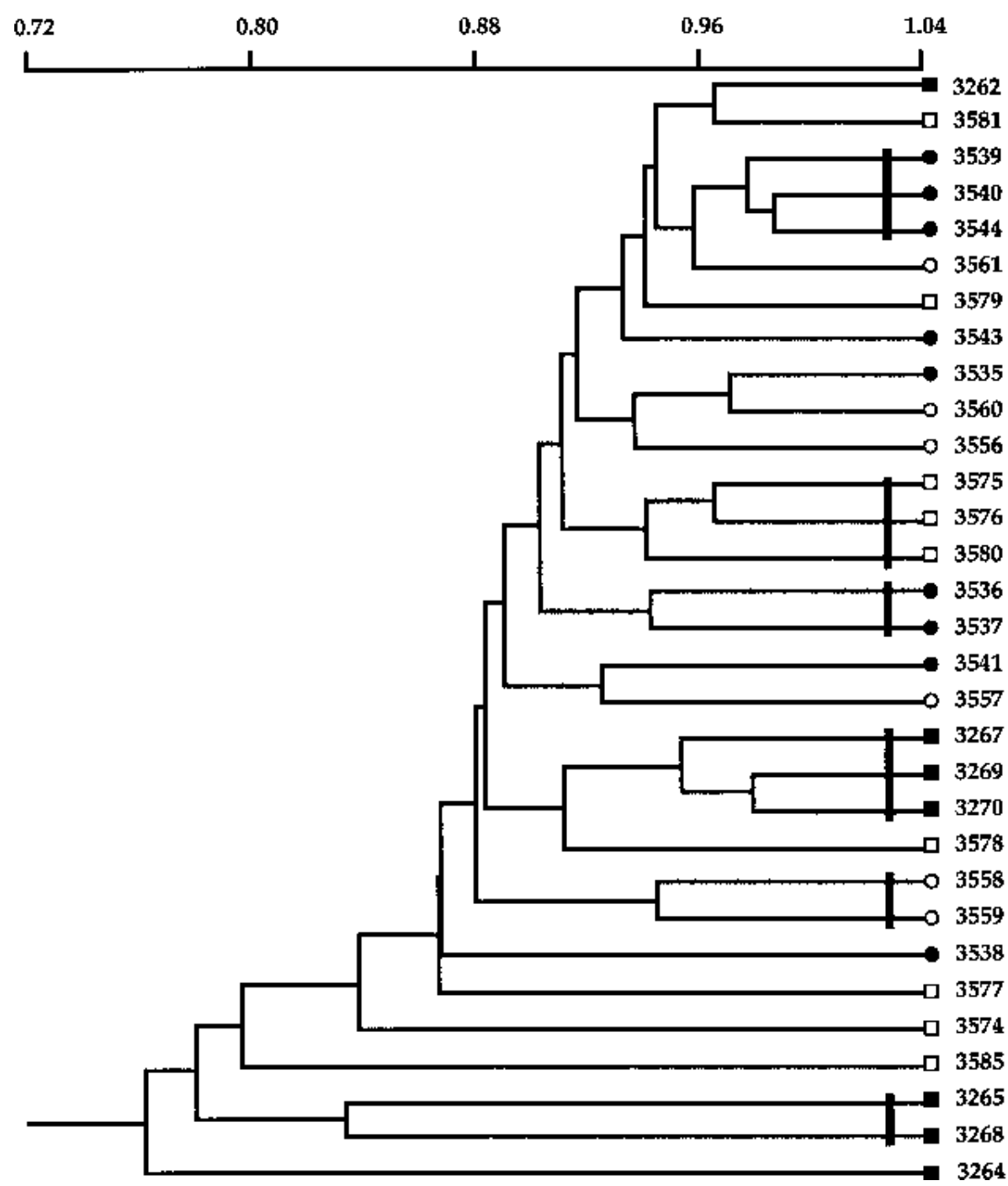

tics related to the allelic diversity found in the four geographic regions. More than $71 \%$ of all alleles detected were found in each region, with an average of $80 \%$ across the four regions. On average, each region has only two unique alleles (i.e., that were not found in any other region). No alleles have been found that are unique to and fixed within a region.

Sixty-one percent of all alleles detected were common to all four regions (data not shown). Almost $75 \%$ of the alleles were found in three of the four regions, and $84 \%$ were found in two or more regions. Only $16 \%$ of alleles were exclusive to a single region. Four alleles ( $8 \%$ of the total) were found in only a single population. All four of these alleles had frequencies above 0.05 , which places them in the category of locally common alleles as defined by Marshall and Brown (1975).

\section{Discussion}

Plant species differ markedly in the way genetic diversity is partitioned between populations and among individuals within populations. The pattern of partitioning is correlated with the mating system and life history parameters (Hamrick and Godt, 1989). Species that are primarily selfed and short-lived have most of their genetic diversity partitioned among populations, while outcrossing perennial species appear to contain most of their diversity within populations. Our results are consistent with this pattern. In fact, the wild $M$. sieversii plants tested in this study represent a panmictic population. Two lines of evidence support this conclusion. First, the phenogram (Fig. 2) shows a few hierarchical subgroupings at the regional level, but this relationship breaks down at higher level groupings. Thus, with few exceptions, sib families from a single

Fig. 2. Phenogram showing results of UPGMA cluster analysis of $M$. sieversii accessions using Nei's genetic identity, $I$, as similarity measure. Sib families are labeled with germplasm ID number of the maternal parent. Geographic origin of maternal parents are indicated graphically: solid square = Uzbekistan, open square $=$ Kyrgyzstan, solid circle $=$ Kazakhstan-Topolevka, open circle $=$ Kazakhstan-Lepsinsk. Vertical lines on the cluster diagram denote clusters containing sib families that are most closely related to sib families from the same geographic region.

sib families from their own region, the other 16 sib families were most closely related to sib families from other regions. Furthermore, all sib families were more closely related to sib families from another region than they were to at least one sib family from their own region. For example, the three sib families from Topolevka, 3539,3540 , and 3544, were most closely related to one another, but were next most closely related to sib family 3561 from Lepsinsk, and then to the cluster containing sib family 3262 from Uzbekistan and 3581 from Kyrgyzstan.

AMOVA analysis revealed (data not shown) that $85 \%$ of the allozyme variation found in this $M$. sieversii germplasm is attributable to differences among sib families within a population. There is comparatively little variation (15\%) among regions and no $(0 \%)$ variation among populations within regions. Table 3 shows statisgeographical region or population are no more likely to be closely related to one another than they are to sib families from other geographical regions or populations. Second, AMOVA indicates that over five times more variation is found within regions than between regions, and there is no variation among populations. This result and the summary statistics for allelic diversity (Table 3) suggest that much of the diversity present in $M$. sieversii can be found in a single population within a single geographic region. Because no alleles have been found that were fixed and unique to a region, it appears that there is no strong geographic partitioning of alleles.

To use information on the partitioning of genetic diversity in a species to determine a collecting strategy, it is useful to classify alleles into four different types: widespread and common, widespread and rare, local and common, and local and rare (Marshall and Brown, 1975). Since alleles that are widespread and common will be sampled regardless of the sampling strategy, and sampling of either type of rare allele is a function of available resources (Brown and Marshall, 1995), only the collection of locally common alleles can be affected by sampling strategy (Marshall and Brown, 1975). Locally common alleles are of particular interest to germplasm collectors, since these may be alleles that are responsible for adaptation to local conditions. 
In this study, only four out of 51 alleles discovered were locally common. To satisfactorily sample such alleles, Brown and Briggs (1991) suggested sampling 50 to 100 individuals per (interbreeding) population from as many diverse and different habitats occupied by the populations as possible, rather than sampling more extensively from a single habitat. They emphasized collecting from as many distinct fruit as possible to increase the number of pollination events and pollen sources at different times from different microhabitats.

Although collecting different fruit is a relatively simple task in $M$. sieversii, collecting from as many different populations as possible is more difficult, since the expense of visiting diverse geographic regions in central Asia is high. Specialized transport (off-road vehicles or helicopters) is often required, and costs for these can be prohibitively expensive. Research by Yonezawa (1985) and Yonezawa and Ichihashi (1989) examined sampling strategies when travel costs are high. Using numerical analyses, these workers showed that to maximize genetic information per unit of effort expended, sampling from 10 or fewer plants per population is satisfactory, provided costs for a population visit and transport were not high. If costs per population visit were extreme, however, sample sizes in the hundreds might be more efficient, and fewer populations can be visited with the same overall amount of information obtained (Yonezawa, 1985). Yonezawa and Ichihashi (1989) conclude that in predominantly outcrossed plants (such as M. sieversii), samples of a few hundred seeds per population might be adequate for sampling the diversity in that population, and emphasis should be placed on number of plants sampled, rather than on number of seeds per plant. Based on these considerations, we conclude that the genetic diversity in $M$. sieversii can be captured most efficiently by a thorough sampling of a few large populations of plants from a few regions. Locally common alleles will be sampled roughly in proportion to the number of populations visited.

Two factors may have biased the sampling of maternal parents and offspring used in this study. The first was a severe prebloom frost of 1993 that limited the number of maternal parents from which fruit could be sampled. This may have biased sampling toward frost-tolerant genotypes, if such genotypes exist. On the other hand, local cooperators reported that anthers and pollen production did not appear to be affected by this freeze, so paternal contribution to sib families may have been little affected by the frost. The second potential source of bias was the low germination rates for the 1989 seeds. This may have resulted in isozyme profiles that differed from what would have been found with a higher germination rate. Still, the summary statistics shown in Tables 2 and 3 suggest that the Uzbekistan allelic diversity detected was not radically different from that found in the other three regions.

Furthermore, the number of enzyme alleles per locus found in this study are typical of values that have been found in previously published work on woody perennials (Hamrick and Godt, 1989).

Table 3. Allozyme allelic diversity summarized by region for 259 plants of Malus sieversii.

\begin{tabular}{lcccc}
\hline \hline Region & $\mathrm{A}_{\text {tot }}{ }^{\mathrm{z}}$ & $\mathrm{P}_{\mathrm{r}}^{\mathrm{y}}$ & $\mathrm{U}^{\mathrm{x}}$ & Percent polymorphic loci \\
\hline Uzbekistan & 38 & 0.75 & 2 & 83.3 \\
Kazakhstan-Topolevka & 45 & 0.88 & 4 & 94.4 \\
Kazakhstan-Lepsinsk & 36 & 0.71 & 0 & 83.3 \\
Kyrgyzstan & 43 & 0.84 & 2 & 88.8
\end{tabular}

${ }^{\mathrm{z}} \mathrm{A}_{\text {tot }}=$ number of alleles plus phenotypes detected in region (out of a possible 51).

${ }_{\mathrm{y}} \mathrm{P}_{\mathrm{r}}=$ ratio of number of alleles plus phenotypes found in a region to total number of alleles plus phenotypes found in all regions.

${ }^{x} \mathrm{U}=$ number of unique alleles plus phenotypes found in each region.
Excluding the population where only one offspring from one maternal parent was analyzed, in our data the number of alleles per locus per population ranged from 1.42 to 2.33 (Table 2) for an average and standard error of $1.90( \pm 0.15)$, while the number of alleles per locus for the species was 2.75 (Table 2). Hamrick and Godt (1989) reported that for long-lived woody perennials, the average number of alleles per locus across populations was 1.79 $( \pm 0.06)$, while the average number of alleles per locus across this type of species was $2.19( \pm 0.09)$. Thus, judging by number of alleles per locus, the enzyme data from this study was actually a bit more diverse than is typically found for long-lived perennial species.

When compared to Malus species in a previous apple isozyme study (Dickson et al., 1991), M. sieversii shows significantly more genetic diversity. The mean number of alleles per locus was 2.75 in the $M$. sieversii sample compared to 1.75 (M. angustifolia), 1.75 (M. coronaria), 2.083 (M. ioensis), and 2.083 (M. fusca) (Dickson et al., 1991). In addition, 94\% of the $M$. sieversii loci were polymorphic, compared to $58 \%$ to $67 \%$ of loci in the other four Malus species (Dickson et al., 1991). The results cited from woody perennials in general and from Malus species in particular strongly suggest that the potential sources of sampling bias probably had minimal effect on observed diversity in our study and that our conclusions are valid for devising a collecting strategy for $M$. sieversii.

\section{Literature cited}

Barnes, M.F. 1993. Leaf peroxidase and catechol oxidase polymorphism and the identification of commercial apple varieties. N.Z. J. Crops Hort. Sci. 21:207-210.

Bournival, B.L. and S.S. Korban. 1987. Electrophoretic analysis of genetic variability in the apple. Scientia Hort. 31:233-243.

Brown, A.H.D. and J.D. Briggs. 1991. Sampling strategies for genetic variation in ex situ collections of endangered plant species, p. 99-119. In: D.A. Falk and K.E. Holsinger (eds.). Genetics and conservation of rare plants. Oxford Univ. Press, New York.

Brown, A.H.D. and D.R. Marshall. 1995. A basic sampling strategy: theory and practice, p. 75-91. In: L. Guarino, V.R. Rao, and R. Reid (eds.). Collecting plant genetic diversity. CAB Intl. Oxon, U.K.

Cardy, B.J., C.W. Stuber, and M.M. Goodman. 1980. Techniques for starch gel electrophoresis of enzymes from maize (Zea mays L.). Dept. of Stat. Mimeo Series No. 1317, N.C. State Univ., Raleigh.

Chevreau, E. and F. Laurens. 1987. The patterns of inheritance in apple (Malus $¥$ domestica Borkh.): Further results from leaf isozyme analysis. Theor. Appl. Genet. 75:90-95.

Dickson, E.E., S. Kresovich, and N.F. Weeden. 1991. Isozymes in North American Malus (Rosaceae): Hybridization and species differentiation. System. Bot. 16:363-375.

Edlefsen, L.E. and S.D. Jones. 1986. GAUSS programming language manual. Aptech Systems, Kent, Wash.

Excoffier, L. 1993. AMOVA 1.5 Analysis of molecular variance. Computer program supplied by the author. Geneva, Switzerland.

Excoffier, L., P.E. Smouse, and J.M. Quattro. 1992. Analysis of molecular variance inferred from metric distances among DNA haplotypes: Application to human mitochondrial DNA restriction data. Genetics 131:479-491.

Forsline, P.L. 1995. Adding diversity to the National Apple Germplasm Collection: Collecting wild apple in Kazakhstan. New York Fruit Quarterly 3:3-6.

Forsline, P.L., E.E. Dickson, and A.D. Djangaliev. 1994. Collection of wild Malus, Vitis, and other fruit species in Kazakhstan and neighboring republics. HortScience 29:433. (Abstr.) 
Hamrick, J.L. and M.J.W. Godt. 1989. Allozyme diversity in plant species, p. 43-63. In: A.H.D. Brown, M.T. Clegg, A.L. Kahler, and B.S. Weir (eds.). Plant population genetics, breeding, and genetic resources. Sinauer Associates, Sunderland, Mass.

Manganaris, A.G. 1989. Isoenzymes as genetic markers in apple breeding. PhD diss. Univ. of London.

Marquard, R.D. and C.R. Chan. 1995. Identifying crabapple cultivars by isozymes. J. Amer. Soc. Hort. Sci. 120:706-709.

Marshall, D.R. and A.H.D. Brown. 1975. Optimum sampling strategies in genetic conservation, p. 53-80. In: O.H. Frankel and J.G. Hawkes (eds.). Crop genetic resources for today and tomorrow. Cambridge Univ. Press, Cambridge, U.K.

Menendez, R.A., F.E. Larsen, and R. Fritts, Jr. 1986. Protein and isozyme electrophoresis and isoelectric focusing for the characterization of apple clones. Scientia Hort. 29:211-220.

Morgan, J. and A. Richards. 1993. The book of apples. Ebury Press, London.

Nei, M. 1972. Genetic distance between populations. Amer. Naturalist 106:283-292.

Rohlf, F.J. 1994. NTSYS-pc, version 1.80. Exeter Software, Setauket, N.Y. Selander, R.K., M.H. Smith, S.Y. Yang, W.E. Johnson, and J.B. Gentry.
1971. Biochemical polymorphism and systematics in the genus Peromyscus, I. Variation in the old-field mouse(Peromyscus polionoties). Studies in genetics VI. Univ. Texas Publ. 7103:49-90.

Sneath, P.H.A. and R.R. Sokal. 1973. Numerical taxonomy. W.H. Freeman and Co., San Francisco.

Torres, A.M. 1989. Isozyme analysis of tree fruits, p. 192-205. In: D.E. Soltis and P.S. Soltis (eds.). Isozymes in plant biology. Dioscorides Press, Portland, Ore.

Weeden, N.F. and R.C. Lamb. 1985. Identification of apple cultivars by isozyme phenotypes. J. Amer. Soc. Hort. Sci. 110:509-515.

Weeden, N.F. and R.C. Lamb. 1987. Genetics and linkage analysis of 19 isozyme loci in apple. J. Amer. Soc. Hort. Sci. 112:865-872.

Wendel, J.F. and N.F. Weeden. 1989. Visualization and interpretation of plant isozymes, p. 5-45. In: D.E. Soltis and P.S. Soltis (eds.). Isozymes in plant biology. Dioscorides Press, Portland, Ore.

Yonezawa, K. 1985. A definition of the optimal allocation of effort in conservation of plant genetic resources - with application to sample size determination for field collection. Euphytica 34:345-354.

Yonezawa, K. and H. Ichihashi. 1989. Sample size for collecting germplasm from natural plant populations in view of the genotypic multiplicity of seed embryos borne on a single plant. Euphytica 41:91-97. 